\section{Australian Journal of \\ Crop Science}

\title{
Morphological traits and resistance to Egyptian broomrape weed (Orobanche aegyptiaca Pers.) in tobacco under greenhouse condition
}

\author{
Zienab Porkabiri ${ }^{1}$, Naser Sabaghnia ${ }^{{ }_{1}}$, Rahmatollah Ranjbar ${ }^{2}$, Hamid Hatami Maleki ${ }^{1}$ \\ ${ }^{1}$ Department of Plant Production and Genetics, Faculty of Agriculture University of Maragheh, P.O. Box 55181- \\ 83111, Maragheh, Iran \\ ${ }^{2}$ Urmia Tobacco Research Center, Urmia, Iran
}

*Corresponding author: sabaghnia@maragheh.ac.ir; sabaghnia@yahoo.com

\begin{abstract}
Broomrape (Orobanche aegyptiaca Pers.) is a debilitating holoparasiting weed in tobacco (Nicotiana tabacum L.) fields with devastating effects on its production. In this study, the reaction of 26 tobacco genotypes was evaluated against broomrape weed in randomized complete block design with three replications under greenhouse condition. Tobacco genotypes were planted in both non-inoculated and inoculated conditions where the soil of inoculated pots was mixed with $0.06 \mathrm{~g}$ of broomrape seed. The genotype by trait (GT) biplot explained $66 \%$ of the total variation of the standardized data and the polygon view of GT presented for 11 traits showed 5 vertex genotypes. Genotype $\mathrm{G} 20$ was the best in terms of leaf properties (length, width, number and area), and stem girth while G14 was the best genotype against broomrapes number as well as fresh and dry weight of broomrapes. Genotype G4 was identified for good performance in plant height and fresh weight total while G19 and G26 were best genotypes in terms of total fresh weight. Based on vector view biplot, a strong positive association among leaf properties, number of broomrapes, fresh and dry weight of broomrapes, and among plant height, fresh weight and dry weight of leaf yield were detected. According to ideal genotype biplot, genotype G20 followed by G3, G13 and G24 were the most favourable genotypes regarding all of the measured traits. The plant height, leaf number per plant and stem girth could be considered as effective selection criteria evolving high yielding genotypes. Finally, genotypes G26 and G19 are good candidates for improving most of the measured traits and for obtaining resistance to the Egyptian broomrape.
\end{abstract}

Keywords: biplot, correlation, Nicotiana tabacum L., leaf yield.

Abbreviations: GT_genotype $\times$ trait, $\mathrm{PH}_{-}$plant height, LL_leaf length, LW_leaf width, LN_number of leaf per plant, SG_stem girth, LA_leaf area, FWT_total fresh weight of leaf yield, DWT_total dry weight of leaf yield, BN_broomrapes number per plot, FWB_fresh weight of broomrapes, DWB_dry weight of broomrapes.

\section{Introduction}

Tobacco is one of the most important non-food crops widely grown worldwide on industrial scale. Belonging to the family Solanaceae, it comes in a variety of species and is known as a natural amphidiploid arisen by hybridization N. sylvestris and N. tomentosiformis (Ren and Timko, 2001; Murad et al., 2002). Besides the popularly known economic importance of tobacco leaves, its seeds contain high percentages of nonedible oil making it an alternative source for biofuel production (Giannelos et al., 2002), and thanks to its high nicotine content, tobacco stalk can be used to produce pesticides (Radojičić et al., 2008). Intensive cultivation of tobacco has been adopted to control weeds and improve yield performance of the crop while preventing soil degradation by wind and/or runoff erosion (Benham et al., 2007). So far, numerous types of tobacco have been defined by different criteria such as natural habitat, intended use, curing method, morphological characteristics, and biochemical properties (Ren and Timko, 2001; Hatami Maleki et al., 2011). Genetic variation has been explored within crop species to meet consumption requirements by introducing desirable genes. Modification of underlying heredity and study of the genetic diversity in tobacco have been of interest for the purpose of the genetic base broadening in breeding programs (Wenping et al., 2009; Darvishzadeh et al., 2011; El-Morsy et al., 2009). Accordingly, the study of tobacco genotypes is important not only for germplasm investigation, but also for the choice of parents in breeding. The results of genetic diversity study provide estimates of genetic variation among different projects. Various materials can be used for this propose. Morphological traits have been used to research the genetic variation of tobacco (Lei et al., 1997; Zhang et al., 2005).

The Egyptian broomrape (Orobanche aegyptiaca Pers.) is known to cause serious losses in the yield of many crops, so that it is very important to keep this parasitic weed controlled, especially because of its small seeds which are shed in large numbers. In general, the seeds will germinate only if exposed to germination stimulants which occur in root exudates of host plant. It is the major holoparasite on tobacco, with yield losses up to $100 \%$ having been recorded 
in the Middle East, Mediterranean areas, and south-eastern Europe (Ashrafi et al., 2008). However, it can be troublesome for some other crops such as legumes, and its economic importance is more extensive. Several strategies such as cultural practices or chemical control have been developed for controlling the Egyptian broomrape, none of which proved successful completely, because applying herbicides is difficult due to its direct connection to host plants, predominantly subterranean nature of the weeds, and the fact that the weed produces too many small seeds (Mariam and Suwanketnikom, 2004; Buschmann et al., 2005). Another approach followed to tackle this parasitic weed problem is breeding to achieve resistant or tolerant crops and. As of current, the most promising results in this respect have been those obtained by Pieterse and Verkleij, (1991). However, the Egyptian broomrape may end up overcoming the resistance or tolerance because of its high genetic variation, with such ability of the host being determined by mono-genes or oligo-genes. Being the result of a combination of several mechanisms, resistance or tolerance to the Egyptian broomrape is generally considered critical to successful implementation of integrated pest management programs (Rubiales et al., 2003a). Therefore, the host genetics is considered to be a basis for further research, especially in connection with breeding programs for resistant or tolerant crops due to economic importance of related crops. The present study was performed to study the inter-relationship of tobacco leaf yield and morphological traits as well as their relation with the Egyptian broomrape using genotype by trait biplot method. The information so derived could be employed to formulate better breeding strategies and select appropriate methods for developing new high-yield tobacco genotypes with potential resistance or tolerance to Egyptian broomrape.

\section{Results}

\section{Polygon view of biplot}

The biplot explained $66 \%$ of total variation in the yield. Fig. 1 shows a polygon view of the biplot drawn by connecting crosses that were farthest from the biplot origin; these vertex genotypes refer to either the best or the worst yield in one or more traits. Passing through the biplot origin, perpendicular lines are drawn to each side of the polygon (equality lines between different genotypes) to facilitate visual comparison of the genotypes (Yan and Tinker, 2006). The genotypes at each vertex of the polygon in the biplot were the best in terms of the trait(s) found within the sector demarcated by any two lines intersecting at the origin of the polygon. Based on Fig. 1, G20 was the best in terms of leaf length (LL), leaf width (LW), leaf number per plant (LN), stem girth (SG) and leaf area (LA), and is indicating its potential for being used as parent in the development of outstanding variants of the above traits. The G14 was the best genotype in terms of the broomrapes number (BN) per plot, fresh weight of broomrapes (FWB) and dry weight of broomrapes (DWB). G4 was identified for its good performance in terms of plant height (PH) and total fresh weight (FWT), rather than other traits, while $\mathrm{G} 19$ and G26 were the best genotypes in terms of dry weight total (DWT). The G5 was also a vertex genotype but no trait was found in its respective sector, indicating that the genotype was not outstanding for any of the measured traits (Fig. 1).

\section{Vector view of biplot}

A vector was drawn from the biplot origin to each marker of the traits to facilitate visualization of the relationships between and among the traits, so that a correlation coefficient can be approximated for any pair of traits by cosine of the angle between their vectors; accordingly, the two traits were deemed as positively correlated if the angle was smaller than $90^{\circ}$, negatively correlated if the angle was larger than $90^{\circ}$, and independent if the angle was $90^{\circ}$, with traits of longer vectors being more responsive to the crosses and vice versa (Yan and Rajcan, 2002; Rubio et al., 2004,). The followings can be inferred from Fig. 2: leaf length (LL), leaf width (LW) and leaf area (LA) were completely and positively correlated to each other; broomrapes number (BN) per plot, fresh weight of broomrapes (FWB) and dry weight of broomrapes (DWB), were positively associated to each other, and plant height (PH), fresh weight total (FWT) and dry weight total (DWT) were positively correlated to each other, as indicated by extremely acute angles. Nevertheless, no association was found between either of LL, LW and LA, in one hand, and FWT and DWT Similarly, no correlation was observed between $B N, F W B$ and DWB, in one hand, and LL, LW and LA, on the other hand. As for the relationship between agronomic traits, the most prominent relations noticed from the biplot revealed that BN, FWB and DWB were highly yet negatively correlated to with FWT and DWT (Fig. 2). According to Bayat et al., (2014), a significant positive correlation was observed between dry leaf yield and fresh weight of leaf and plant height.

\section{Ideal genotype and dry wright}

Mean effects of the traits across the genotypes were examined by defining an average tester coordinate (ATC) axis and an average (virtual) genotype as ideal genotype (indicated by a circle at positive end of the axis). The Ideal genotype was the one with extremely large PC1 scores (high traits' means) along with small absolute) PC2 scores (low variability); therefore, the genotypes with above-mentioned characteristics were selected, with the rest of the genotypes discarded. Thus, followed by the genotypes G3, G13 and $\mathrm{G} 24$, the genotype $\mathrm{G} 20$ was the most favourable genotype regarding all of the measured traits thanks to its low distance from horizontal axis. With reference to the ideal genotype, the best genotypes were ranked as G16 > G18 > $\mathrm{G} 21>\mathrm{G} 18>\mathrm{G} 9>\mathrm{G} 15>\mathrm{G} 4>\mathrm{G} 1$, and the most unfavourable genotypes were ranked as $\mathrm{G} 5>\mathrm{G} 23>\mathrm{G} 11>\mathrm{G} 10>\mathrm{G} 17$ (Fig. 3). In order to improve of DWT in the tobacco and given the ranking of the genotypes (Fig. 4), it was found that the genotypes G26 and G19 were the most favourable genotypes for producing high DWT values, with large potentials for enhancing dry leaf yield in tobacco. Ranking of the other best genotypes based on the high DLW was G4 > $\mathrm{G} 9>\mathrm{G} 22>\mathrm{G} 18>\mathrm{G} 20>\mathrm{G} 3>\mathrm{G} 16>\mathrm{G} 1>\mathrm{G} 6$ and the ranking of the most unfavourable genotypes based on the DLW potential was $\mathrm{G} 14>\mathrm{G} 7>\mathrm{G} 17>\mathrm{G} 11>\mathrm{G} 12$ (Fig. 4). 
Table 1. Name and origin of the studied tobacco genotypes.

\begin{tabular}{|c|c|c|c|c|}
\hline Code & Name & Type & Curing Method & Origin \\
\hline G1 & North Carolina & Virginia & Flue-cured & USA \\
\hline G2 & Montcalm Brum 258 & Virginia & Flue-cured & Switzerland \\
\hline G3 & Pee Dee & Virginia & Flue-cured & Germany \\
\hline G4 & Madar & Oriental & Sun-cured & Iran \\
\hline G5 & Hicks 26-110 & Virginia & Flue-cured & USA \\
\hline G6 & Vir REE & Virginia & Flue-cured & USA \\
\hline G7 & NC TC 52 & Virginia & Flue-cured & unknown \\
\hline G8 & T.R 1 & Oriental & Sun-cured & Iran \\
\hline G9 & K 394 & Virginia & Flue-cured & USA \\
\hline G10 & Rosecan Nela & Virginia & Flue-cured & Canada \\
\hline G11 & Coker 254 36-150 & Virginia & Flue-cured & USA \\
\hline G12 & All Purpase & Virginia & Flue-cured & USA \\
\hline G13 & South Carolina & Virginia & Flue-cured & USA \\
\hline G14 & Coker 176-97 & Virginia & Flue-cured & Great Britain \\
\hline G15 & X 55 & Oriental & Sun-cured & Turkish \\
\hline G16 & Bell & Virginia & Flue-cured & USA \\
\hline G17 & Samatra 9 & Semi-Oriental & Sun-cured & unknown \\
\hline G18 & Coker 319 & Virginia & Flue-cured & USA \\
\hline G19 & Coker 258 & Virginia & Flue-cured & USA \\
\hline G20 & Vir Aurea & Virginia & Flue-cured & unknown \\
\hline G21 & Vir Yold & Virginia & Flue-cured & Germany \\
\hline G22 & C 319 & Virginia & Flue-cured & USA \\
\hline G23 & Coker 411 & Virginia & Flue-cured & USA \\
\hline G24 & Coker 55 & Virginia & Flue-cured & unknown \\
\hline G25 & Coker 411 26-130 & Virginia & Flue-cured & USA \\
\hline G26 & Coker 254 & Virginia & Flue-cured & USA \\
\hline
\end{tabular}

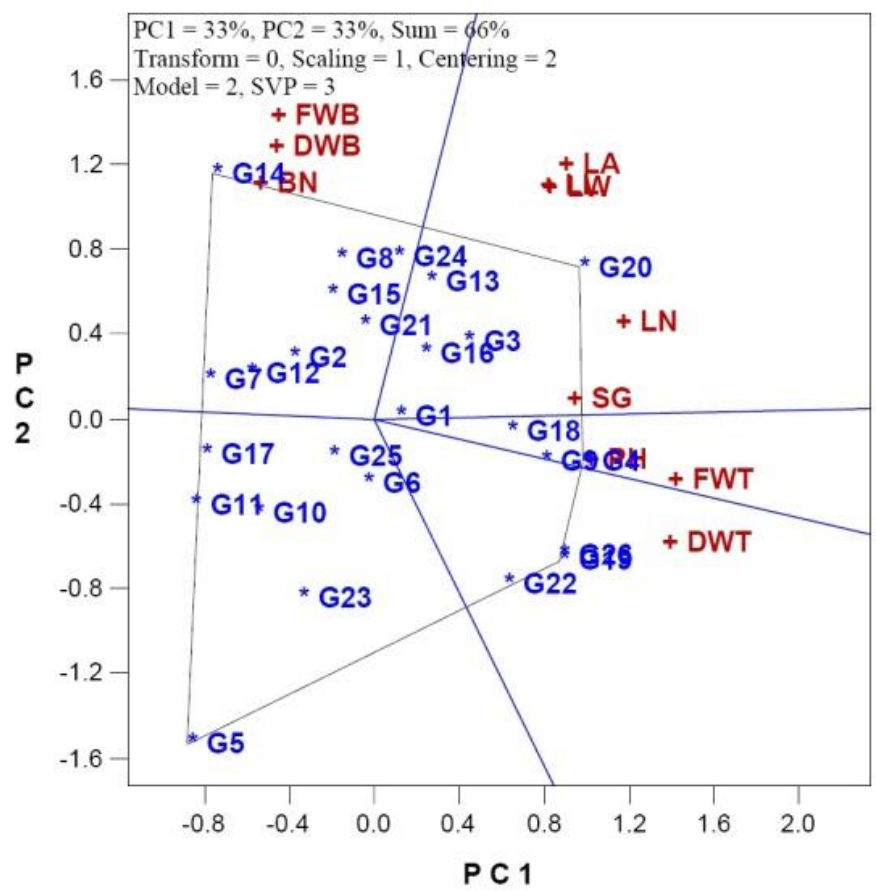

Fig 1. Polygon view GT biplot, showing which genotype had the highest values for which of measured traits across 26 tobacco genotypes under greenhouse condition.Traits are plant height (PH), leaf length (LL), leaf width (LW), leaf number per plant (LN), stem girth (SG), leaf area (LA), fresh weight total (FWT) of leaf yield, dry weight total (DWT) of leaf yield, broomrapes number (BN) per plot, fresh weight of broomrapes (FWB) and dry weight of broomrapes (DWB). 


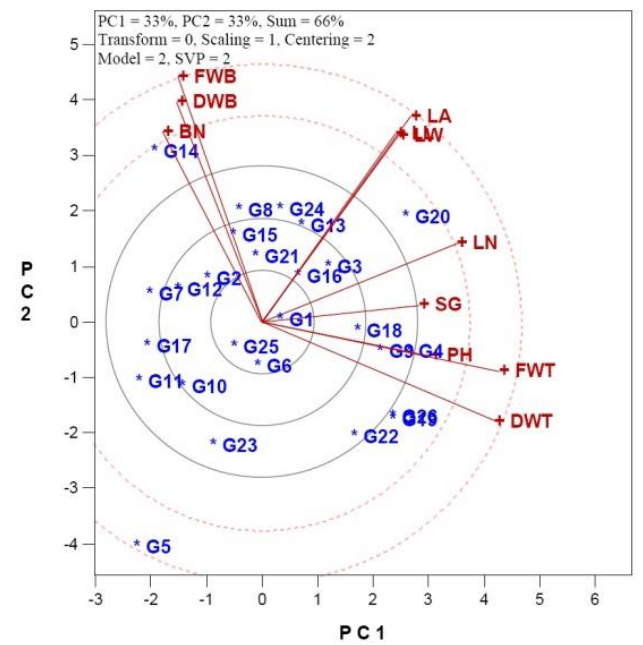

Fig 2. Vector view GT biplot, showing the interrelationship among measured traits for 26 different tobacco genotypes under greenhouse condition. Traits are plant height (PH), leaf length (LL), leaf width (LW), leaf number per plant (LN), stem girth (SG), leaf area (LA), fresh weight total (FWT) of leaf yield, dry weight total (DWT) of leaf yield, broomrapes number (BN) per plot, fresh weight of broomrapes (FWB) and dry weight of broomrapes (DWB).

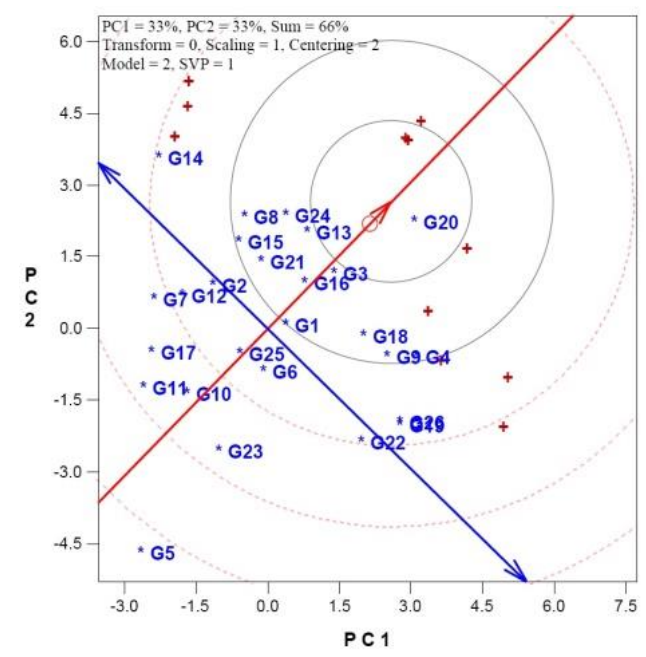

Fig 3. Ideal entry (genotype) view of GT biplot, showing the relationships of 26 tobacco genotypes with ideal entry under greenhouse condition which indicated which genotypes were close to ideal genotype.

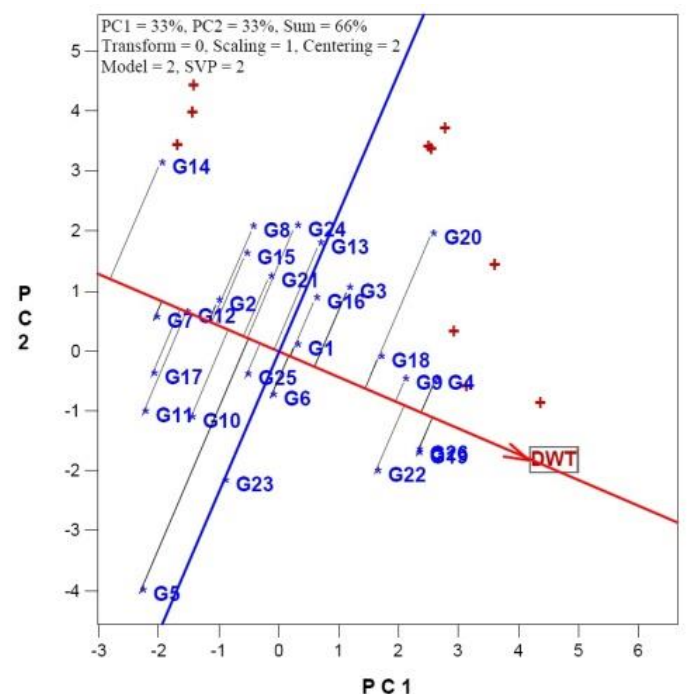

Fig 4. Ranking of genotypes based on dry weight total (DWT) as leaf yield according to GT biplot method under greenhouse condition which indicated which genotypes had the high values for DWT. 


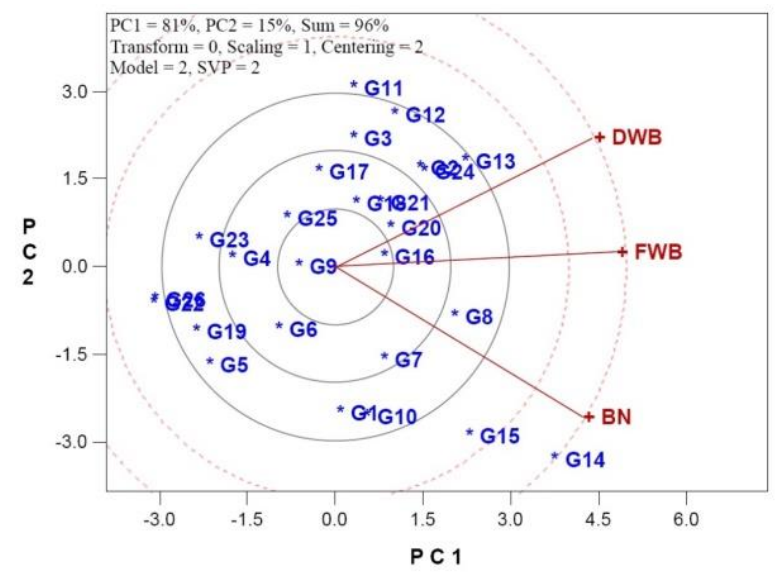

Fig 5. Vector view GT biplot, showing the interrelationship among related traits of broomrapes for 26 different tobacco genotypes under greenhouse condition. Traits are broomrapes number (BN) per plot, fresh weight of broomrapes (FWB) and dry weight of broomrapes (DWB).

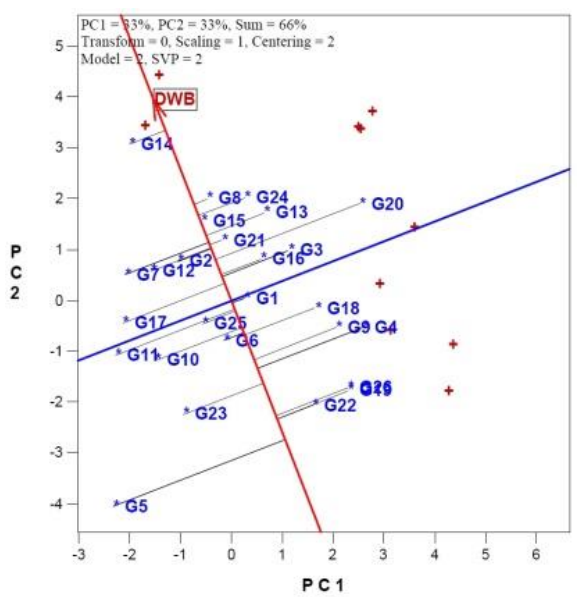

Fig 6. Ranking of genotypes based on d dry weight of broomrapes (DWB) weed according to GT biplot method under greenhouse condition which indicated which genotypes had the low values for DWB.

\section{Egyptian broomrape}

Used for evaluating the Egyptian broomrape (Orobanche aegyptiaca Pers.) were three traits measurements: number of broomrapes per plot, fresh weight of broomrapes (FWB) and dry weight of broomrapes. The results indicated a positive correlation between DWB and FWB, but no significant correlation was observed between DWB and BN (Fig. 5). Thus, it seems that the lightest and heaviest plants were obtained with the largest and smallest numbers of broomrapes per plot, respectively. Based on the target trait (dry weight of broomrapes), the best genotype was G14 followed by G8, G24, G15, G13, G7, G2, G12, G21 and G20, the most unfavourable genotypes were ranked as $5>\mathrm{G} 22>$ $\mathrm{G} 26=\mathrm{G} 19>\mathrm{G} 23$ (Fig. 6). In order to improve resistance of tobacco to Egyptian broomrape and enhance its leaf yield performance, genotypes G26 and G19 could be considered. Darvishzadeh (2016) studied the reaction of 89 tobacco genotypes to broomrape and reported two genotypes (TB 22 and 'Kramograd NHH 659) as the most resistant genotypes to broomrape weed.

\section{Discussion}

The polygon view of biplot identified several vertex genotypes (G4, G5, G14, G20, G26 and G19) and their related genotypes located in different sectors. It was found that the genotypes are good candidates for heterosis examination (Yan and Kang, 2003). Also, vertex genotypes G19, G21, G26 and their sector's genotypes (e.g. G1, G3, G4, G9, G13, G16, G18, G21, G22 and G24) could be used for improving fresh and dry leaf yield traits in tobacco breeding program. The leaf properties including leaf length, leaf width and leaf area are important for improving leaf yield potential and defining breeding strategies for genetic improvement of dry leaf yield (Bayat et al., 2014). In this investigation, no positive association was found between yield and leaf properties. The relative contributions from different traits (plant height, leaf number per plant and stem girth) of economical crop yield to the identification of desirable genotype found in this study by the traits compared to the biplot procedure proposed by biplot are similar to those found in other crop studies; white lupin (Rubio et al., 2004), rapeseed (Sabaghnia et al., 2010) and safflower (Baljani et al., 2015). The vector view of biplot indicated positive correlation of dry weight of broomrapes to fresh weight of broomrapes, no significant correlation between dry weight of broomrapes and number of broomrapes was seen. The most resistant genotype to dry weight of broomrapes was G5 followed by G22, G26, G19 and G23.

The need for the application of biplot based on so-called site regression (SERG) model is because of its capability to identify the most superior genotypes and facilitate the identification of such genotypes (Crossa et al., 2002). This 
investigation showed that, the SERG model can be used to analyse patterns of genotypes and traits and provide a valuable prediction. It is clear that, the biplot is an excellent tool for visualizing the interaction of genotypes based on trait data as it can graphically address the research questions (Yan, 2014) and compare the results with those of conventional methods. The methodology brings about several advantages including graphical presentation features, further interpretative nature, indication of interrelationships among the tobacco traits, simple identification of possible which-won-where patterns, and independently culling based on multiple traits (Yan and Rajcan, 2002; Yan et al., 2007). Biplot analysis of genotype by trait tables is a typical example of applying biplot analysis to study multivariate data based on singular value decomposition of trait-standardized two-way table, with the standard deviation for each trait. It can help understand the relationships among traits and help identify traits that are correlated, traits that are redundantly measured, and traits that can be used by being indirectly selected for another trait. It also helps visualize the trait profiles of genotypes, which is important for parent as well as genotype selection (Yan and Kang, 2003).

Genetic variations are important to allow breeders to deal with changing environmental conditions. Although there are some local genotypes available to breeders, but most traits exhibited variations that are yet to be investigated in tobacco. The data obtained in this research could be useful for breeders along their efforts to increase crop yield. The correlation analysis for the tobacco yield and other traits indicated large variations, suggesting that the plant height, number of leafs per plant and stem girth are the primary selection criteria for higher leaf yield in tobacco. Studying fifteen tobacco genotypes based on some morphological traits, Zeba and Isbat (2011) indicated significant differences among the traits including those in plant height, number of leafs, leaf length, leaf width and stem girth traits. Similarly, large genetic variations were found for some morphological traits: leaf area, number of leafs and leaf length (Honarnejad and Shoaie-Deylami, 2004).

The biplot revealed that, the plant height, number of leafs per plant and stem girth traits are suitable for indirect selection of tobacco dry leaf. It seems that, in order to improve exotic tobacco genotypes or lines, one should select genotypes with higher values of the above mentioned traits. Also, almost all of the studied genotypes, especially G26 and G19, were good candidates for improving most of the measured traits thanks to their good genetic variability in our plant materials, developing some resistance to the Egyptian broomrape.

\section{Materials and Methods}

\section{Experiment and plant materials}

In this research, twenty five tobacco genotypes (Table 1) were studied at a greenhouse in Urmia Tobacco Research Centre, Iran. The studied genotypes were breeding lines or cultivars from different countries procured either by Cooperation Centre for Scientific Research Relative to Tobacco (Paris, France), or by Iran's Tirtash Tobacco Research Centre. Seeds of genotypes were sown in bed at a rate of approximately $5 \mathrm{~g} \mathrm{~m}^{-2}$. Following the sowing stage, a fine layer of well-fermented and sieved sheep manure was spread on top of the beds. Obtained seedlings of $12 \mathrm{~cm}$ in height were transplanted to ceramic plant pots filled with 10 $\mathrm{kg}$ of sterilized soil. Then, the soil in each pot was manually mixed with $0.06 \mathrm{~g}$ of Egyptian broomrape seeds and transplanted during $12 \mathrm{~cm}$ height. The experiment was performed according to a randomized complete block design with three replications, with each replication consisting of one pot. Standard agronomical practices were applied during the growing season, irrigation was done twice a week. Harvesting was performed at technical maturity at the end of growing season and different morphological traits were recorded, including plant height $(\mathrm{PH})$, leaf length (LL), leaf width (LW), number of leaf per plant (LN), stem girth (SG) and leaf area (LA). Also, total fresh weight (FWT) of leaf yield and total dry weight (DWT) of leaf yield were measured and broomrapes number (BN) per plot, fresh weight of broomrapes (FWB) and dry weight of broomrapes (DWB) were recorded in each pot.

\section{Statistical analysis}

For analysis of the genotype $\times$ trait (GT) interaction, biplot was used to show the two-way pattern of genotypes' traits in a biplot based on the following formula:

$$
\frac{\alpha_{i j}-\beta_{j}}{\sigma_{j}}=\sum_{n=1}^{2} \lambda_{n} \xi_{i n} \eta_{j n}+\varepsilon_{i j}=\sum_{n=1}^{2} \xi_{i n}^{*} \eta_{j n}^{*}+\varepsilon_{i j}
$$

where $\alpha_{i j}$ is the mean of genotype $\mathrm{i}$ for trait $\mathrm{j}, \beta_{j}$ is the mean of all genotypes in trait $\mathrm{j}, \sigma_{i j}$ is the standard deviation of trait $\mathrm{j}$ among the genotypes, $\lambda_{n}$ is the singular value for the principal component $\mathrm{n}(\mathrm{PCn}), \xi_{\text {in }}$ and $\eta_{j n}$ are scores for genotype $\mathrm{i}$ and trait $\mathrm{j}$ on $\mathrm{PCn}$, respectively, and $\varepsilon_{i j}$ is the residual associated with genotype $i$ in trait $j$. To achieve symmetric scaling between the genotype scores and the trait scores the singular value $\lambda_{n}$ has to be absorbed by the singular vector for genotypes $\xi_{\text {in }}$ and that for traits $\eta_{j n}$. That is, $\xi_{i n}^{*}=\xi_{i n} \lambda_{n}^{0.5}$ and $\eta_{j n}^{*}=\eta_{j n} \lambda_{n}^{0.5}$. Because of $\mathrm{n}=2$, only PC1 and PC2, are retained in the model and such this model tends to be the best for extracting pattern as well as noise rejecting. Because the traits were measured in various units, the biplots were generated using the standardized values of the trait means using GGEbiplot software (Yan, 2001).

\section{Conclusion}

The GT biplot revealed that plant height, leaf number per plant and stem girth traits are suitable for indirect selection of tobacco dry leaf. It appears, to improve exotic tobacco genotypes or lines by selecting for genotypes with higher values of the above mentioned traits. Also, almost all of studied genotypes especially genotypes G26 and G19 are good candidates for improving most of the measured traits due to existence of good genetic variability in our plant materials and for obtaining resistance to the Egyptian broomrape. 


\section{Acknowledgments}

We wish to thank kindly Professor Wei-Kai Yan (Eastern Cereal Oilseed Research Centre of Agriculture and Agri-Food Canada) for making available a time-limited version of GGEbiplot as "testBiplotxlsx".

\section{References}

Ashrafi ZY, Alizadeh HM, Sadeghi S (2008) Effect of soil solarization on the control of Egyptian broomrape (Orobanche aegyptiaca) and yield improvement of cucumber (Cucumis sativus) grown in greenhouse. Am Eurasian J Agric Environ Sci. 4: 775-782.

Baljani R, Shekari F, Sabaghnia N (2015) Biplot analysis of trait relations of some safflower (Carthamus tinctorius L.) genotypes in Iran. Crop Res. 50: 63-73.

Bayat M, Darvishzadeh R, Soleimani F, Reza Alavi S (2014) Sequential path analysis for determining interrelationships between yield and related traits in tobacco (Nicotiana tabacum L.) under normal and abiotic stress conditions. Genetika. 46: 815-829.

Benham BL, Vaughan DH, Laird MK, Ross BB, Peek DR (2007) Surface quality impacts of conservation tillage practices on burley tobacco production systems in southwest Virginia. Water Air Soil Pollut. 179: 159-166.

Buschmann H, Gonsior G, Sauerborn J (2005) Pathogenicity of branched broomrape (Orobanche ramosa) populations on tobacco cultivars. Plant Pathol. 54: 650-656

Crossa J, Cornelius PL, Yan W (2002) Biplots of linear-bilinear models for studying crossover genotype $\times$ environment interaction. Crop Sci. 42: 619-633.

Darvishzade R (2016) Genetic variability, structure analysis, and association mapping of resistance to broomrape (Orobanche aegyptiaca Pers.) in tobacco. J Agr Sci Tech. 18: 1407-1418.

Darvishzadeh R, Alavi SR, Sarafi A (2011). Genetic variability for chlorine concentration in oriental tobacco genotypes. Arch Agron Soil Sci. 57: 167-177.

El-Morsy SI, Dorra MDM, El-Hady EAA, Hiaba AA, Mohamed A (2009) Comparative studies on diploid and tetraploid levels of Nicotiana alata. Acad J Plant Sci. 2: 182-188.

Giannelos PN, Zannikos F, Stournas S, Lois E, Anastopoulos G (2002) Tobacco seed oil as an alternative diesel fuel: physical and chemical properties. Ind Crops Prod. 16: 1-9

Hatami Maleki H, Karimzadeh G, Darvishzadeh R, Sarrafi A (2011) Correlation and sequential path analysis of some agronomic traits in tobacco (Nicotiana tabacum L.) to improve dry leaf yield. Aust J Crop Sci. 5: 1644-1648.

Honarnejad R, Shoai-Deylami M (2004) Gene effect, combining ability and correlation of characterstics in F2 populations of Burley tobacco. J Sci Tech Agric Nat Resour. 8: 135-147.

Lei YH, Xu ML, Huang XY (1997) Tobacco collection in the Yunnan province. Science and technology publishing company of Yunnan, Yunnan, pp. 1-20.
Mariam EG, Suwanketnikom R (2004) Screening of Tomato (Lycopersicon esculentum Mill.) Varieties for Resistance to Branched Broomrape (Orobanche ramose L.). Kasetsart J. 38: 434-439.

Murad L, Lim KY, Christopodulou V, Matyasek R, Lichtenstein CP, Kovarik A, Leitch AR (2002) The origin of tobacco's T genome is traced to a particular lineage within Nicotiana tomentosiformis (Solanaceae). Am J Bot. 89: 921-928.

Pieterse AH, Verkleij JAC (1991) Genetic variability in Orobanche (broomrape) and Striga (witchweed) and its implications for host crop resistance breeding. In: Rozema J, Verkleij JAC (eds) Ecological responses to environmental stresses. Tasks for vegetation science, vol 22. Springer, Dordrecht.

Radojičić V, Nikolić M, lćitović S (2008) Some possibilities of tobacco waste utilization. Ecological truth 08, Proceedings of the VIII Scientific Professional Conference, Ecological Truth, Soko Banja, pp. 481-484.

Ren, N, Timko MP (2001) AFLP analysis of genetic polymorphism and evolutionary relationships among cultivated and wild Nicotiana species. Genome. 44: 559571.

Rubio J, Cubero JI, Martín LM, Suso MJ, Flores F (2004) Biplot analysis of trait relations of white lupin in Spain. Euphytica. 135: 217-224.

Sabaghnia N, Dehghani H, Alizadeh B, Mohghaddam M (2010) Genetic analysis of oil yield, seed yield, and yield components in rapeseed using additive main effects and multiplicative interaction biplots. Agron J. 102: 1361-1368.

Wenping LI, Zhu L, Zhao S (2009) Correlation and path coefficient analysis and Euclidean distance clustering for several characters in tobacco germplasm resource. Chinese Tobacco Sci. 30: 59-63.

Yan W (2001) GGE biplot - A Windows application for graphical analysis multienvironment trial data and other types of two-way data. Agron J. 93: 1111-1118.

Yan W (2014) Crop variety trials: Data management and analysis. John Wiley \& Sons Press.

Yan W, Hunt LA, Sheng Q, Szlavnics Z (2000) Cultivar evaluation and mega-environment investigation based on the GGE biplot. Crop Sci. 40: 597-605.

Yan W, Kang MS (2003) GGE biplot analysis: A graphical tool for geneticists, breeders, and agronomists. CRC Press.

Yan W, Kang MS, Ma B, Woods S, Cornelius PL (2007) GGE biplot vs. AMMI analysis of genotype-by-environment data. Crop Sci. 47: 643-655.

Yan W, Rajcan I (2002) Biplot evaluation of test sites and trait relations of soybean in Ontario. Crop Sci. 42: 11-20.

Yan W, Tinker NA (2006) Biplot analysis of multienvironment trial data: Principles and applications. Can J Plant Sci. 86: 623-645.

Zeba N, Isbat M (2011) Multivariate analysis for yield and yield contributing traits in FO and F1 generations in tobacco (Nicotiana tabacum). J Exper Biosci. 2: 101-106.

Zhang HY, Liu XZ, He CS, Zheng CM (2005) Random amplified DNA polymorphism of Nicotiana tabacum L. cultivars. Biol Planta. 49: 605-607. 